\title{
The ontology of theoretical modelling: models as make-believe
}

\author{
Adam Toon \\ Department of Philosophy \\ University of Bielefeld \\ P.O. Box 100131 \\ 33501 Bielefeld, Germany \\ adam.toon@uni-bielefeld.de
}

\begin{abstract}
The descriptions and theoretical laws scientists write down when they model a system are often false of any real system. And yet we commonly talk as if there were objects that satisfy the scientists' assumptions and as if we may learn about their properties. Many attempt to make sense of this by taking the scientists' descriptions and theoretical laws to define abstract or fictional entities. In this paper, I propose an alternative account of theoretical modelling that draws upon Kendall Walton's 'make-believe' theory of representation in art. I argue that this account allows us to understand theoretical modelling without positing any object of which scientists' modelling assumptions are true.
\end{abstract}

\section{Keywords}

Models - Representation - Fiction - Imagination 


\section{Introduction: theoretical modelling}

Suppose we are interested in predicting the motion of a bob bouncing on the end of a spring. One way to do this would be to model the bouncing spring as a simple harmonic oscillator. In doing so we make a number of assumptions: we take the bob to be a point mass $m$ subject only to a uniform gravitational field and a linear restoring force exerted by a massless frictionless spring with spring constant $k$ attached to a rigid surface. Following Nancy Cartwright, let us call this our 'prepared description' of the bouncing spring. ${ }^{1}$ Of course, we realise that this description is false, and that a full or 'unprepared' description would make reference to the air resistance on the bob, the mass of the spring, and so on. However, making these assumptions enables us to use Hooke's Law to write down a simple equation of motion for the bouncing spring, $m d^{2} x / d t^{2}=-k x$, where $m$ is the mass of the bob, $k$ is the spring constant and $x$ is the displacement from the equilibrium position. We can then solve this equation to give the position of the bob at any time after its release, and our predictions may be rather accurate.

Let us call such cases theoretical modelling to distinguish them from the use of physical models. ${ }^{2}$ The contrast between the two is instructive. If an engineer wishes to learn about the properties of a bridge she might first construct a physical scale model of it. By finding out about the properties of the model she hopes to learn something about the properties of the bridge itself. When we model the bouncing spring, we do not build any physical object that satisfies our prepared description or equation of motion. Indeed, no actual, concrete object satisfies our assumptions: no real bob is a point mass or is subject to a perfectly uniform gravitational field, no real spring has zero mass or is entirely free from friction, and so on. And yet we often think and talk about theoretical and physical modelling in similar ways. What we do when we model the bouncing spring, we might say, is to construct a simplified or idealised version of it, which we investigate in order to learn about the more complex behaviour of the spring itself. Even though there is no actual, concrete, simple harmonic

1 Cartwright (1983).

2 Note that I use the term 'theoretical' only to indicate that scientists do not construct a physical model of the system modelled and not to imply that model is derived from some existing theory, like Newtonian mechanics. Recent case studies suggest scientists must often go beyond existing theory to model a system (for example, see Morgan and Morrison (1999)). 
oscillator that satisfies our prepared description and equation of motion, we often make statements that appear to refer to such an object. For example, we might remark that 'the point mass oscillates sinusoidally' or that 'the force exerted by the spring is linear'. We also speak as if we may learn about that object. For example, we might discover that the bob in our model oscillates sinusoidally or that its period of oscillation is given by the formula $T=2 \pi \sqrt{m / k}$.

Theoretical modelling is extremely common in the sciences. It is usually the case that a system must be simplified or idealised in some way before it can be given a theoretical treatment. In this paper, I will address three key questions raised by cases of theoretical modelling such as our model of the bouncing spring. The first question asks how we should interpret our prepared description and equation of motion. Despite Cartwright's terminology, it is clear that they are not straightforward descriptions of the bouncing spring: we do not claim that the bob is a point mass or that the spring is frictionless, because we know this to be false. And yet they do look like a description. In fact, our prepared description and equation of motion are an example of what Martin Thomson-Jones calls a 'description of a missing system': they look just like a description of some actual, concrete object, and yet we realise that there are no such systems that would satisfy this description. ${ }^{3}$ The second question for our account of theoretical modelling asks how we are to understand our subsequent talk about our model, which appears to assume that there is an object that satisfies this description. (Thomson-Jones refers to this as the 'face value practice'.) Finally, our theory should be able to make sense of the idea that we may learn about our model of the bouncing spring.

One way to answer these questions is to insist that, while no actual, concrete object satisfies our prepared description and equation of motion, there is some other object that does satisfy them. This is the route taken by Ronald Giere. On Giere's account, our prepared description and equation of motion define an abstract object. It is this object that it the model. ${ }^{4}$ Talk about our model might then be understood as talk about this abstract object and learning about the model a matter of discovering its properties. Giere's view is not without problems, however. For example, Thomson-Jones observes that since there are no actual, concrete objects that fit our prepared description and equation of motion, the abstract objects Giere posits must be non-spatiotemporal. But then how can such objects possess the spatiotemporal properties we

3 Thomson-Jones (2010).

4 For example, see Giere $(1988,1999,2004)$. 
appear to attribute to them, such as oscillating with period $T ?^{5}$ In response to such concerns, some have suggested that, rather than abstract objects, theoretical models should be understood as fictional entities, like Emma Bovary or Count Dracula. ${ }^{6}$ Of course, the status of fictional entities is itself subject to considerable debate and it remains to be seen whether this suggestion may be developed to provide an adequate account of theoretical modelling.

In this paper I propose an alternative account of theoretical modelling. I also look to works of fiction, drawing on Kendall Walton's 'make-believe' theory of representation in art. ${ }^{7}$ But I will not advocate the view that theoretical models are fictional entities. In fact, my account will not posit any object that satisfies our prepared description and equation of motion (Section 3). Nevertheless, I will argue that it explains how we can learn about theoretical models (Section 4) and allows us to understand talk about theoretical models (Section 5). First, however, I need to provide a brief introduction to Walton's theory of representation and how I believe it may be applied to scientific models.

\section{Models as make-believe}

\subsection{Walton's theory: props and games}

According to Walton, representations function as props in games of make-believe. Suppose that some children play a game in the woods in which they imagine tree stumps to be bears. In Walton's terminology, in this game the tree stumps are props and the convention that the children establish by their agreement that stumps 'count as' bears is a principle of generation. Together, props and principles of generation make propositions fictional. To say that a proposition is fictional, on Walton's theory, is to say that there is a prescription to imagine it. The fact that the proposition is fictional is a fictional truth. Thus, given the principle that stumps 'count as' bears, if a participant in the game comes across a stump in a thicket, they are to imagine that there is a bear there; it is fictional there is a bear there.

5 Thomson-Jones (2010).

6 The suggestion that models might be understood as fictional entities is found in Godfrey-Smith (2006) and Frigg (2006). Contessa (2010) follows this approach by developing his own 'dualist' account of fictional entities, while Frigg (2010) draws on Walton's theory of fiction (see note 15). Thomson-Jones (2007) also explores versions of this view.

7 Walton (1990). The suggestion that Walton's theory may be applied in the context of scientific modelling is also made in Barberousse (2006). See also Barberousse and Ludwig (2000). 
What is fictional in a game of make-believe need not be the same as what is imagined. A stump which remains hidden under a pile of leaves still makes it fictional that a bear lurks there. An oddly shaped stump might prompt a child to imagine a wolf and not a bear, but the proposition that there is a wolf before them is only imagined, not fictional. Fictional truths therefore possess a certain kind of 'objectivity'; participants can be unaware of fictional truths and mistaken about them.

The stumps in the children's game are not representations, however. A representation, in Walton's sense, is not something that merely happens to be used as a prop; it is something of which it is the function to serve as such. Walton's theory does not aim to analyse our ordinary use of the term 'representation'. Most history books, newspaper articles or biographies, Walton thinks, do not count as representations in his sense. Instead, he aims to 'carve out a new category' that may be applied to what we might call 'works of fiction', including novels, paintings, sculptures, plays and so on. ${ }^{8}$ All of these different works, Walton argues, function as props in games of make-believe.

There are important differences between many works of fiction and the stumps in the children's game, of course. As well as prescribing imaginings, the stumps are also objects of those imaginings: the children imagine of the stumps that they are bears. This is not a necessary condition for something to count as a prop, however, and while some works of fiction do prescribe imaginings about themselves (we are to imagine that the first chapter of the novel Dracula is an excerpt from a journal, for example), many do not. The principle that wherever there is a stump, fictionally, there is a bear, was established by participants in the game by explicit stipulation. But Walton's theory does not demand that principles of generation be established in this way, nor that they be explicitly formulated. And indeed, many implicit rules are likely to operate in the children's game: it may well be that if the stump in the thicket is taller than the stump under the leaves, then, fictionally, the bear in the thicket is taller than the bear hiding in the leaves. In the case of novels or paintings, principles of generation are difficult to specify explicitly, complex, and vary from case to case.

8 Walton (1990, p. 2). 


\subsection{Models}

I believe we may regard scientific models as representations, inWalton's sense. Models, I think, function as props in games of make-believe. In physical modelling, the prop is a physical object, such as the architect's scale model of the bridge. In theoretical modelling, like our model of the bouncing spring, the prop is usually a prepared description and equation of motion. In some cases, the prop might be a diagram or picture. Just as for novels or paintings, the principles of generation governing the games in which these props function are complex and vary from case to case. In each case, however, the model represents in virtue of prescribing us to imagine things. Where a model represents an actual system, it does so by prescribing imaginings about that system; in Walton's terminology, it makes propositions about the system fictional.

I provide a fuller defence of this account of representation in modelling elsewhere. ${ }^{9}$ In this paper, my aim is to show how the account may be used to explain those features of theoretical modelling discussed in Section 1. Nevertheless, a few clarifications are in order.

First, the term 'fiction'. Sometimes, when we call something 'fictional' or a 'work of fiction' we do so to imply that it is false or even deceitful. Walton does not use the term in this way. To say a proposition is fictional in Walton's sense is simply to say that there is a prescription to imagine it. This is perfectly compatible with truth. If a child screams when he comes across a stump in the woods, it will probably be fictional that he screams; it is both fictional and true that the child screams. To call something a work of fiction in Walton's sense is simply to say that it functions as a prop in games of make-believe. Any, or even all, of the propositions that the work makes fictional may be true. ${ }^{10}$ The position I advocate is therefore distinct from what Arthur Fine calls fictionalism. ${ }^{11}$ As Fine characterises it, fictionalism is an anti-realist position which argues that a scientific theory may be reliable without being true and without the entities it invokes existing. To classify a model as a representation, and thus a work of fiction, in Walton's sense, is to say nothing about the truth of the propositions it prescribes or about the existence of the entities it invokes.

9 Toon $(2010,2008)$.

10 Of course, some will disagree with this characterisation of the divide between works of fiction and non-fiction. That debate need not concern us here.

11 Fine (1998). 
Second, although I do claim that models employ the same form of representation that Walton ascribes to works of fiction, I do not deny that there are many important differences between the two (although I think it is less clear if and where a line may be drawn between them). Similarly, to claim that some scientific drawings depict their subjects would not prevent us recognising the enormous differences between those drawings and Surrealist paintings.

Third, like Walton, I do not claim to analyse our ordinary use of the term 'representation', which is as loose and variable with regard to scientific models as it is elsewhere. For some, the term carries implications of realism, or at least empirical adequacy. This is not the case on my account: the propositions a model makes fictional need not be true nor even empirically adequate. I think this is as it should be: many bad models, which fail to meet standards of truth or empirical adequacy, still represent their objects, and our theory of representation must be able to accommodate them. Of course, we will then wish to draw further distinctions among models, distinguishing good from bad along perhaps various different dimensions. Walton's theory provides us with the resources to do so, since even physical models generate propositions about their objects. But I will not take up this task here. Instead I want now to return to the case of theoretical modelling set out in Section 1.

\section{Re-interpreting theoretical modelling}

How are we to understand the prepared description and equation of motion that we write down when we model the bouncing bob? I believe that they may be understood in the same way that Walton understands works of fiction. Consider the following passage from The War of the Worlds:

The dome of St. Paul's was dark against the sunrise, and injured, I saw for the first time, by a huge gaping cavity on its western side. ${ }^{12}$

Clearly, this is not a description of St. Paul's Cathedral: when Wells wrote this he was not claiming that there really was a hole in the side of St. Paul's. Nevertheless, on Walton's view, the passage still represents St. Paul's; St. Paul's is an object of The War of the Worlds. Something is an object of a representation on Walton's theory if the representation prescribes

12 Wells (2005, p. 170). 
us to imagine propositions about it. Usually, Walton thinks, when we read a linguistic work of fiction that uses proper names, we take ourselves to be prescribed to imagine things of the normal referents of those names. On this view, the above passage represents (the actual) St. Paul's, because it requires readers to imagine certain things of St. Paul's, namely that it has a large hole in its dome. In Walton's terminology, the passage makes it fictional that St. Paul's has a large hole in its dome.

Without taking a stance in the debate over proper names in fiction, I think we may use Walton's analysis to provide an account of our prepared description and equation of motion. We saw in Section 1 that these are not straightforward descriptions of the bouncing spring. Nevertheless, I believe, they do represent the spring, in Walton's sense: they represent the spring by prescribing imaginings about it. When we put forward our prepared description and equation of motion, I think, those who are familiar with the process of theoretical modelling understand that they are to imagine certain things about the bouncing spring. Specifically, they are required to imagine that the bob is a point mass, that the spring exerts a linear restoring force, and so on.

Using Walton's terminology, we may say that our prepared description and equation of motion make it fictional that the bob is a point mass, that it is subject to a linear restoring force and so on. However, recall that, on Walton's theory, to say a certain proposition is fictional is not to say that it is true in some fictional world; it is merely to say that there is a prescription to imagine it. To say that The War of the Worlds makes it fictional that St. Paul's is damaged is not to say that there is some fictional realm in which it is true that St. Paul's is damaged. Similarly, to say that it is fictional that the bob is subject to a linear restoring force is not to say that there is any object of which this is true. It is merely to say that we are to imagine of the actual bob that it is subject to a linear restoring force.

On the account I propose, then, there is no object that satisfies the prepared descriptions and equations of motion that scientists write down when they model a system. This account of theoretical modelling is therefore rather different from that offered by Giere. It also differs from those that take models to be fictional entities. Fictional entities arise from works of fiction containing passages such as this (from Dracula):

The Count smiled, and as his lips ran back over his gums, the long, sharp, canine 
teeth showed out strangely. ${ }^{13}$

Intuitively, it seems that such passages are about someone called Count Dracula. If we say 'Dracula has long teeth' it appears we assert something true of that person. In light of this, some argue that we must grant that Count Dracula does exist in some sense, perhaps as a form of abstract or Meinongian non-existent entity. Those who take theoretical models to be fictional entities compare our prepared description and equation of motion to passages like this from Dracula. The idea seems to be that, just as the novel Dracula gives rise to a fictional Count Dracula and determines his properties, so our prepared description and equation of motion give rise to a fictional, idealised bouncing spring and determine its properties. Talk about our model is then talk about this fictional entity.

This is not my view. I do not take our prepared description and equation of motion to parallel passages about fictional entities, like this passage from Dracula. Instead, I have argued that they should be understood in the same way as Walton understands passages like that quoted above from The War of the Worlds. There is no pressure on us to postulate a fictional, damaged, St. Paul's for this passage to represent; the passage simply represents the actual St. Paul's. Similarly, on my account, our prepared description and equation of motion do not give rise to a fictional, idealised bouncing spring since they represent the actual bouncing spring. (And, as we shall see in Section 5.1, discourse about our model may also be understood without postulating a fictional bouncing spring that it refers to.)

Both Giere's account, and those that take models to be fictional entities, offer an indirect, two-stage view of scientific modelling: prepared descriptions and equations of motion define an abstract or fictional entity, which, in turn, represents (or, as Giere would put it, is used to represent) the system being modelled (Fig. 1). By contrast, I propose a direct view. Our prepared description and equation of motion represent the bouncing spring directly, by prescribing imaginings about it (Fig. 2). Thus, my view is not that our prepared description and equation of motion prescribe us to imagine an idealised bouncing spring system, which then represents the actual system in some way. Rather, I claim that our description and equation prescribe us to imagine things about the actual system: we imagine of the actual bob that it is a point mass and of the actual spring that it is massless, and so on. ${ }^{14}$

13 Stoker (1994, p. 33).

14 My account therefore differs from that offered in Frigg (2010). Frigg also draws on Walton's theory of fiction, but he 


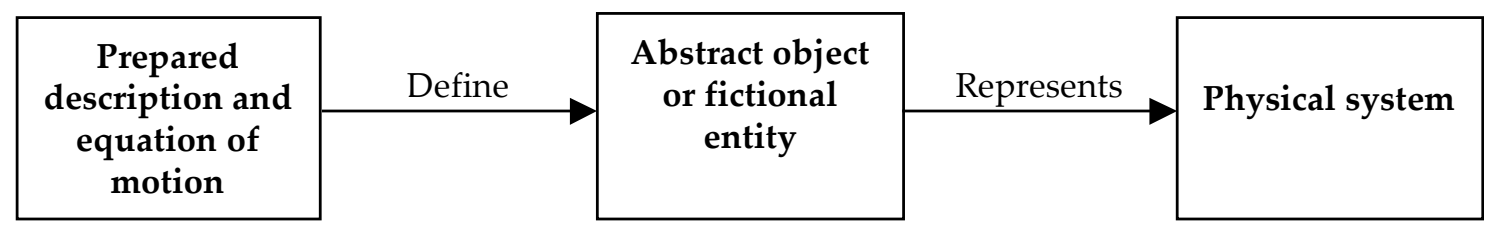

Figure 1: Indirect views of theoretical modelling

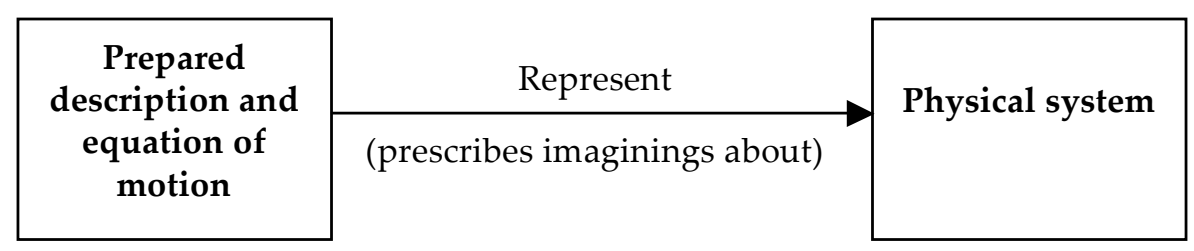

Figure 2: Models as make-believe

In the remainder of this paper, I will show how this interpretation of our prepared description and equation of motion allows us to understand other important features of theoretical modelling. At this point, however, I want to emphasise that the account I have described is intended to apply only to prepared descriptions and theoretical laws scientists formulate when they model some actual system. There may be other passages, also appropriately called 'descriptions of missing systems', that cannot be interpreted in this way. For example, suppose we wrote down the same prepared description and equation of motion, not while modelling some particular bouncing spring, but in order to instruct someone how to model such systems. (We might begin by saying 'suppose there were a bob bouncing on a spring'.) In this case, it seems that there will be no actual system that the description and equation represent. And yet, arguably, they are still representational: intuitively, they represent a normal bouncing spring, even though there is no actual bouncing spring that they represent. Must we postulate a fictional bouncing spring system that the description and equation represent, just we might postulate a fictional Count Dracula for Stoker's novel to represent? There are many scientific models that present this problem, the most obvious examples being models of entities we know believe not to exist, like mechanical models of the ether. I consider such models elsewhere. ${ }^{15}$ For the present discussion, it is sufficient to note that the question of whether such models represent fictional entities is distinct from the question of

advocates an indirect view of theoretical modelling, on which prepared descriptions and equations of motion ask us to imagine an 'imagined concrete system' which then bears some other form of representation relation to the system being modelled.

15 Toon $(2009,2010)$. 
whether they are themselves fictional entities. In the case we are considering, even if we take our model to be a fictional idealised oscillator that satisfies our prepared description and equation of motion, we are still left with the problem of saying what this fictional oscillator represents.

\section{Learning about theoretical models}

In Section 3, I offered a way to interpret the prepared descriptions and theoretical laws that scientists write down when model a system which does not require us to postulate any object that they describe. In Section 1, however, I observed that we often speak as if there were such an object and as if we can learn about its properties. I will consider the problem of interpreting talk about our model in Section 5. In this section, I want to show how the account I have proposed can make sense of learning about a theoretical model.

As we have seen, Walton claims that representations are things whose function it is to serve as props in games of make-believe. Those games in which it is the function of a representation to serve as a prop are called authorised games. Representations might be used in different games entirely (a child might use a copy of Dracula as an 'island' in a game of toy soldiers); these are unofficial games. What is fictional in the world of a representation is that which would be fictional in any authorised game and whose fictionality is generated by the work alone. ${ }^{16}$ Thus, it is fictional in the world of The War of the Worlds that London is attacked, that St. Paul's is damaged, and so on. Primary fictional truths are those that are generated directly by the props together with the relevant principles of generation. The presence of the stump in the clearing, together with the principle that stumps count as bears, generates the fictional truth that a bear is in the clearing. Implied fictional truths are generated indirectly by other fictional truths. Dracula makes it fictional that a large dog jumps off a deserted boat that sails into Whitby harbour. Given what we have read so far, we can infer that this dog is the Count in animal form. Even though the text does not directly say so, then, it is fictional that Dracula jumped off a deserted boat that sails into Whitby harbour. The fact that this is fictional is an implied fictional truth: it is fictional that Dracula jumped off the

16 This definition is intended to distinguish the world of the representation from that of the games individuals play with it. When we read a novel, Walton claims, we not only imagine the events it narrates; we often, for example, imagine that we ourselves hear or read about those events. But we are not a character in the novel (Walton 1990, p. 60). 
boat (in part) because it is fictional that a dog jumped off the boat. Thus, we may divide the principles by which fictional truths are generated into two kinds: principles of direct generation and principles of implication. The former are conditional upon the features of the representation; they say, for example, that if a novel contains certain words then certain fictional truths are generated. Principles of implication tell us what further fictional truths are implied by primary fictional truths.

The notion of fictional worlds may also be applied to our model. It is fictional in the world of our model that the bob is a point mass, that the spring exerts a linear restoring force, and so on. These are primary fictional truths: they are generated directly by our prepared description and equation of motion and the principles of direct generation in effect. These principles would appear to be rather simpler than those governing the use of novels or paintings, at least for cases like our model of the bouncing spring. Given a particular prepared description and equation of motion, it seems, we are to imagine that they are true of the system being modelled. (There appears to be no analogue of the deceitful narrator for scientific models, for example.)

These primary fictional truths in turn generate other, implied, fictional truths. They imply, for example, that it is fictional that the bob oscillates sinusoidally and that it reaches its greatest speed when it passes through the equilibrium position. They also imply that, fictionally, the bob oscillates with a period of $T=2 \pi \sqrt{m / k}$. This is fictional in the world of our model even though we did not write down this equation when we formulated our model. Competent users of the model understand that they are to imagine these things to be true of the bouncing spring, given that they are to imagine that it satisfies our prepared description and equation of motion. What principles govern these implications? It is tempting to suggest the principle that if, fictionally, a variable satisfies a certain equation then it should also, fictionally, satisfy its solutions. But often during the course of a calculation, solutions are 'discarded' as having no physical interpretation. (For example, we discard the negative square root for the bob's period of motion.) And, in fact, I believe that principles of implication are more difficult to specify explicitly and will vary from case to case. (To take an obvious example, it seems we make different inferences in models based on classical and quantum mechanics.)

Even without an explicit statement of the various principles of generation, however, this 
account provides us with a way of understanding learning about a theoretical model. This is not a matter of learning facts about any object. Instead, it is a matter of discovering what is fictional in the world of the model. As we saw in the case of the children's game in the woods, what is fictional in a game of make-believe can be unknown to us: the child may not know that it is fictional that a bear is hiding under a pile of leaves. Similarly, we may not know when we formulate our model that it is fictional that the bob oscillates sinusoidally or that its period of oscillation is $T=2 \pi \sqrt{m / k}$. The reason for our ignorance is not the same as in the child's case, however. Our position is more like that of the reader of Dracula who fails to realise that the dog who jumps off the boat in Whitby harbour is the Count. We are quite aware of the state of our props, and of many of the fictional truths these props generate. What we don't know are many other fictional truths that these fictional truths imply. Learning about our model it is a matter of discovering these fictional truths: it is a matter of discovering what further propositions we are required to imagine, once we imagine our prepared description and equation of motion to be true.

The notion of the world of a model also allows us to meet an important objection that might be raised against the account proposed in this paper. One reason for taking models to be abstract or fictional entities that satisfy prepared descriptions and theoretical laws, rather than the descriptions and laws themselves, is that it seems that the same model may be given many different formulations: we produce the same model for the bouncing spring if we write our prepared description in Portuguese or French, for example. The notion of the world of a model allows us account to explain this. Just as different linguistic formulations may define the same abstract or fictional object, so they may generate the same fictional world; that is, they may each prescribe us to imagine the same propositions of the bouncing bob.

\section{Theoretical modelling talk}

Much of our talk about theoretical modelling appears to assume there is an object of which our prepared description and equation of motion are true. And yet the account I have proposed denies that there is such an object, even an abstract or fictional entity. In this section, I consider how we can make sense of such talk. First, in Section 5.1, I will consider statements that appear to state what is 'true in our model', like 'the force exerted by the 
spring is linear' or 'the point mass oscillates sinusoidally'. In Section 5.2, I then consider an example of talk about models that does not fall into this category: what Giere calls 'theoretical hypotheses', that is, statements of the form 'the system is similar to the model in certain respects and degrees'.

\subsection{Talk about what is 'true in the model'}

When we model the bouncing spring we might say things like 'the bob oscillates sinusoidally', 'the force exerted by the spring is linear', 'the system does not dissipate energy', 'no air resistance acts on the bob' or 'the spring has no mass'. If these utterances are taken to express claims about the actual bouncing spring, they are false and known to be so. And yet if we utter them in the context of our model we would appear to assert something true. If a teacher modelled the bouncing spring and asked a student how the bob oscillates, and she replied 'the bob oscillates sinusoidally', she would answer correctly. The student appears to make a straightforward assertion, and yet, on my account, there is no object of which this assertion is true. How can we explain this?

I propose the following analysis: when the student says 'the bob oscillates sinusoidally', what she actually asserts is that the prepared description and equation of motion that the teacher writes down make it fictional that the bob oscillates sinusoidally. In other words, she claims that, given the prepared description and equation of motion, one is supposed to imagine that the bob oscillates sinusoidally. This statement is true and its truth depends only on the prepared description and equation of motion and the relevant rules of generation; it does not depend upon the existence of any object that really does oscillate sinusoidally. On this analysis, then, utterances like 'the bob oscillates sinusoidally', that look like statements about an object that fits our prepared description and equation of motion, turn out to be assertions about what our model prescribes us to imagine about the actual bouncing spring system.

Once again, notice that this account differs from those that take theoretical models to be fictional entities. Proponents of these accounts compare talk about theoretical models to talk about fictional entities like Count Dracula. Even though there is no such person as Count Dracula, we seem to refer to him and discuss his properties, saying things like 'Dracula has 
long teeth'. Similarly, it is argued, even though there are no ideal oscillators, we seem to be able to refer to our model of the bouncing spring and discuss its properties. However, on my account, statements about what is 'true in our model' do not generate the same problem as statements like 'Dracula has long teeth'. This is because I take our prepared description and equation of motion to represent the actual bouncing spring. On my account, statements such as 'the bob oscillates sinusoidally' are like the statement we would make if we said 'St. Paul's is damaged' while reading The War of the Worlds. Since Walton takes the novel to represent St. Paul's itself such statements do not present any problems with fictional entities. We simply claim that it is fictional in the novel that St. Paul's is damaged.

Some statements we make while modelling the system might appear more problematic. For example, suppose we were to say, 'the point mass oscillates sinusoidally' or 'the massless spring exerts a linear restoring force'. On the surface, both of these claims appear to make reference to non-existent entities, specifically, a point mass and a massless spring. Point masses or massless, frictionless springs are certainly not things that we can collect from the lab store cupboard and it is tempting to label them as 'fictional entities'. In fact, however, statements like these also do not generate problems with fictional entities. At the last British general election, cartoons were published that depicted Conservative Party leader Michael Howard as a vampire. Like point masses, vampires do not exist. But if, while looking at one of these cartoons, we were to remark that 'the vampire has long teeth', our statement would not generate the same problem as the statement 'Dracula has long teeth'. Like our prepared description and equation of motion, the cartoon represents an actual object, namely Michael Howard. When we say 'the vampire has long teeth' we may simply take 'the vampire' to refer to Michael Howard, and understand ourselves as claiming that the cartoon makes it fictional that Michael Howard has long teeth. Similarly, if we say 'the point mass oscillates sinusoidally', I think we may understand ourselves as claiming that our model makes it fictional that the bob oscillates sinusoidally, and no troublesome reference to a fictional entity occurs.

At this point, however, we might ask: if what we really assert when we say 'the bob oscillates sinusoidally' is that our model makes it fictional that the bob oscillates sinusoidally, why do we make the assertion in this way? Why not simply say 'it is fictional that the bob oscillates sinusoidally'? One answer is suggested by Walton. Along with his account of representation, 
Walton offers an analysis of discourse about fiction, which rests on the idea that we participate verbally in games of make-believe. ${ }^{17}$ One aim of this analysis is to deal with statements like 'Dracula has long teeth' in a way that does not commit us to fictional entities. But it may also be used to understand statements without any apparent reference to fictional entities, such as 'St. Paul's is damaged' (said in the context of The War of the Worlds). According to Walton, this utterance is an act of pretence. We pretend to assert that St. Paul's is damaged. ${ }^{18}$ In doing so, we indicate that pretending in this way is appropriate in games authorised for Wells' novel. It is appropriate because when we pretend in this way, fictionally, we speak the truth. The reason we, fictionally, speak the truth is, of course, simply that it is fictional in The War of the Worlds that St. Paul's is damaged. On Walton's analysis, then, when we say 'St. Paul's is damaged' we indicate that pretending in this way is appropriate, and in doing so assert that the conditions that make this pretence appropriate are in place; that is, we assert that it is fictional in The War of the Worlds that St. Paul's is damaged.

Walton's analysis provides us with a way of understanding utterances about what is 'true in our model', like 'the bob oscillates sinusoidally' or 'the force exerted by the spring is linear'. When we make these utterances we are engaging in (or perhaps merely specifying) certain acts of pretence. When the student says 'the bob oscillates sinusoidally', for example, she pretends to assert that the bob oscillates sinusoidally. In doing so, she indicates that pretending in this way is appropriate in games authorised for the teacher's model. It is appropriate because the model makes it fictional that the bob oscillates sinusoidally. The student asserts that this is the case by pretending in the way that she does.

\subsection{Other talk about models: Giere's 'theoretical hypotheses'}

Each of the statements I considered in Section 5.1 might be described as statements about what is 'true in our model'. Some statements we make while modelling the system cannot be understood in this way, however. A good example are the 'theoretical hypotheses' that Giere takes to be crucial to the way scientists use models to represent the world. These are statements of the form 'the system is similar to the model in certain respects and degrees'. ${ }^{19}$

17 Walton (1990, Chap. 10).

18 In fact, Walton's theory does not demand that the speaker actually engage in pretence. When we say 'St. Paul's is damaged' we might specify the relevant kind of pretence without exemplifying it.

19 See Giere (2004). 
Even if we reject Giere's view of representation, scientists do make statements like these. And yet this way of talking about theoretical models also seems to rely on there being objects of which our modelling assumptions are true, since when we talk in this way we appear to compare an idealised model system with the world.

We often talk about works of fiction in the same way. When reading The War of the Worlds we might say 'before the Martian invasion, Wells' London is a faithful replica of the city itself'. Even though, on Walton's account, the novel represents London itself, when we say this we appear to commit ourselves to a fictional entity, specifically, something called 'Well's London', which we then compare to the city itself. We do the same with portraits. For example, while standing before a portrait like Jacques-Louis David's Napoleon Crossing the Saint Bernard, we might remark that 'David's Napoleon is taller than the real Napoleon'.

The analysis I offered in Section 5.1 cannot help us to make sense of theoretical hypotheses. Suppose we were to say 'the period of oscillation of the bob in the model is within $10 \%$ of the period of the bob in the system'. We cannot understand ourselves to be claiming that our model makes it fictional that the period of the bob in the model is within $10 \%$ of that of the real bob. Our model prescribes imaginings about the actual bob; it is fictional in our model that there is only one bob (the actual bob) and that it oscillates with period $T=2 \pi \sqrt{m / k}$. Despite this, I think we may still analyse our theoretical hypotheses without commitment to any object that fits our prepared description and equation of motion. When we say 'the period of oscillation of the bob in the model is within $10 \%$ of the period of the bob in the system', we are simply comparing what our model asks us to imagine with what is true of the system. Specifically, we assert that the period of oscillation of the bob has some value $T_{0}$ and that it is fictional in our model that the bob oscillates with period $T_{1}$, where $T_{1}$ is within $10 \%$ of $T_{0}$.

In Section 5.1 I suggested that Walton's pretence account of discourse about fiction might provide an explanation for why we speak about theoretical models in the way that we do. Pretence can also be used to provide an explanation for the way we express comparisons between our model and the world in theoretical hypotheses. But the pretence must now be understood to occur within an unofficial, rather than an authorised, game of make-believe. On Walton's account, much of our talk about works of fiction is to be understood as invoking unofficial games of make-believe. For example, suppose we say 'Bram Stoker created Count 
Dracula'. When we say this we invoke a common unofficial game, in which to write a novel that makes it fictional that a certain character exists is, fictionally, to create that character. When we say 'Bram Stoker created Count Dracula' we indicate that pretending in the way that we do is appropriate in this unofficial game. And, as before, we assert that the conditions responsible for the fact that, fictionally, we speak the truth are in place. This is, we assert that Bram Stoker wrote the novel Dracula. We make an assertion about who wrote the novel by indicating how, fictionally, to speak the truth in the unofficial game we invoke.

Walton's notion of unofficial games allows us to understand theoretical hypotheses as acts of pretence. Our theoretical hypothesis invokes an unofficial game in which it is fictional that there exists both the bob and an entity called 'the model bob' which, fictionally, has all the properties attributed to the bob by the model. By invoking this game we avail ourselves of a convenient way of making assertions about the accuracy of our model: by indicating how to pretend appropriately in this game. When we say 'the period of oscillation of the bob in the model is within $10 \%$ of the period of the bob in the system' we indicate how, fictionally, to speak the truth in our unofficial game, and in doing so we assert that the conditions responsible for our fictionally speaking the truth are in place; that is, we assert that the period of oscillation of the bob has some value $T_{0}$ and that it is fictional in our model that the bob oscillates with period $T_{1}$, where $T_{1}$ is within $10 \%$ of $T_{0}$.

\section{Conclusion}

When scientists produce a theoretical model of a system, they ask others to imagine that the assumptions they make are true of that system. The prepared description and theoretical laws that they write down represent that system directly, by prescribing imaginings about it. There is no need to posit any abstract or fictional object of which the scientists' assumptions are true. Learning about a model is not a matter of discovering facts about any object but of discovering what the model prescribes us to imagine. When we make statements that seem to describe such an object we are simply making claims about what our model asks us to imagine. We do so by indicating to others how to pretend appropriately in games authorised for our model. 


\section{Acknowledgements}

Parts of this paper were presented in talks at the 'Beyond Mimesis and Nominalism' conference held at LSE in June 2006, the PhilosophyWorkshop in Cambridge in June 2006, the CMMGraduate Conference held in Leeds in June 2007, and the 'Scientific Models: Semantics and Ontology' workshop, held in Barcelona in July 2007. Thanks to participants at all of these events, particularly my commentator in Barcelona, Manuel Garcia-Carpintero. Thanks also to Nancy Cartwright, Ronald Giere, Mary Leng, Mauricio Suárez, Paul Teller and Kendall Walton for discussion and correspondence, Stacie Friend for criticism of a draft of this paper, and Martin Thomson-Jones for helpful comments and encouragement. Finally, I would like to thank my supervisor Martin Kusch for his support throughout my $\mathrm{PhD}$, and my advisor, the late Peter Lipton, who will be greatly missed.

Research for this paper was supported by The Arts and Humanities Research Council and The Darwin Trust of Edinburgh. I am very grateful to both of these institutions for their support.

\section{References}

Barberousse, A. (2006). Images of theoretical models. Unpublished paper delivered at A.P.A. Mini-Conference on Scientific Images.

Barberousse, A., \& Ludwig, P. (2000). Les modèles comme fictions. Philosophie, 68, 16-43.

Cartwright, N. (1983). How the laws of physics lie. Oxford: Clarendon Press.

Contessa, G. (2010). Scientific models as fictional objects. Synthese, 172(2), 215-229.

Fine, A. (1998). Fictionalism. In E. Craig (Ed.), Routledge encyclopedia of philosophy. Retrieved 5 Dec 2007, from http://www.rep.routledge.com/article/Q035.

Frigg, R. (2006). Scientific models. In S. Sarkar \& J. Pfeifer (Eds.), The philosophy of science: An encyclopedia, with Stephan Hartmann. New York: Routledge.

Frigg, R. (2010). Models and fiction. Synthese, 172(2), 251-268. 
Giere, R. (1988). Explaining science. Chicago: University of Chicago Press.

Giere, R. (1999). Science without laws. Chicago: University of Chicago Press.

Giere, R. (2004). How models are used to represent reality. Philosophy of Science, 71, S742S752.

Godfrey-Smith, P. (2006). The strategy of model-based science. Biology and Philosophy, 21, $725-740$.

Morgan, M., \& Morrison, M. (1999). Models as mediators. Cambridge: Cambridge University Press.

Stoker, B. (1994). Dracula. (Penguin Popular Classics, 1st ed. 1897).

Thomson-Jones, M. (2007). Missing systems and the face value practice. Retrievable from http://philsci-archive.pitt.edu/archive/00003519.

Thomson-Jones, M. (2010). Missing systems and the face value practice. Synthese, 172(2), 283-299.

Toon, A. (2009). Models as make-believe. PhD thesis, University of Cambridge.

Toon, A. (2010). Models as make-believe. In R. Frigg \& M. Hunter (Eds.), Beyond mimesis and convention: Representation in art and science. Springer-Verlag.

Walton, K. (1990). Mimesis as make-believe. Cambridge: Harvard University Press.

Wells, H. G. (2005). The War of the Worlds (1st ed. 1898). London: Penguin. 